\title{
PERFORMANCE OF FIELD ORIENTED CONTROLLED OPEN-END WINDING INDUCTION MOTOR DRIVE USING NEAREST SUB-HEXAGONAL CENTER PWM TECHNIQUES
}

\author{
Mahamkali RANJIT*, Teegala BRAHMANANDA REDDY ${ }^{* *}$, Munagala SURYA KALAVATHI ${ }^{* * *}$ \\ *Asst.Professor, Department of Electrical and Electronics Engineering, VNR Vignana Jyothi Institute of Engineering and Technology \\ (Autonomous) Hyderabad, Telangana, India, E-mail: ranjit m@vnrvjiet.in \\ ${ }^{* *}$ Professor \& Head, Department of Electrical and Electronics Engineering, G.Pulla Reddy Engineering College (Autonomous) \\ Kurnool, Andhra Pradesh, India, E-mail: tbnr@rediffmail.com \\ ${ }^{* * *}$ Professor, Department of Electrical and Electronics Engineering, JNTUH, Hyderabad, Telangana, India. \\ E-mail: munagala12@yahoo.co.in
}

\begin{abstract}
In this article, performance of field oriented controlled open-end winding induction motor drive (FOCOEWIMD) using nearest sub-hexagonal centre PWM (NSHCPWM)technique is proposed. In the proposed work, two 2-level inverters are used on either side of OEWIM drive to obtain the three-level output voltage. To generate the control signals for the two inverters, NSHCPWM technique is used. In the proposed method reference vector is realized with two components, based on the tip of the reference vector location nearest sub-hexagonal centre is identified, which is one of the switching vector used to generate the control signals for inverter-I and the other component is realized using inverter-II by mapping into the inner sub-hexagon. So that one inverter is used as switching inverter and the other is as clamping inverter. Ripples in torque and stator current are also reduced in the proposed work over conventional SVPWM techniques. Proposed work is analyzed theoretically and the same can be realized using MATLAB/SIMULINK and the corresponding results are presented for different modulation index.
\end{abstract}

Keywords: Field oriented control (FOC), Induction motor drive, Nearest sub-hexagonal centre PWM (NSHCPWM), Open-end winding induction motor (OEWIM).

\section{INTRODUCTION}

Most of the industrial drives are variable speed drives. Out of different AC drives, induction machine becomes popular because of its ruggedness, easy control. Pulse width modulated voltage source inverters are used to control of AC drives. Various PWM techniques like sine PWM, SVPWM, discontinuous PWM techniques are used to control the output voltage of the inverters [2],[57].Different control techniques like $\mathrm{v} / \mathrm{f}$ control, field oriented control(FOC), direct torque control(DTC) are used to control of variable AC drives [11]-[12]. In v/f control, performance of drive is more efficient in steady state but dynamic response of the drive becomes poor. Particularly if the drive is operated with PWM VSI its operation is limited to low voltage and low frequency [11].To obtain the better dynamic performance of ac drive two main vector control techniques are used namely, field oriented control(FOC), direct torque control(DTC).In this work, analysis is carried out by considering only FOC technique. Basic principle of FOC technique is to convert the 3-phase stator currents into two currents. Out of two currents, one is used to establish the magnetic field and the other is used to control the torque [12]. In FOC both the currents are controlled both in magnitude and phase wise independently so that the orthogonal control is obtained between the two current components. Hence FOC drive is operated like separately excited dc drive where independent control of field and armature control is possible [11-12].Basic idea in FOC is to obtain the two currents and rotor flux position. Based on the estimation of rotor flux position FOC is divided into two types; direct method and indirect method. In direct method, rotor flux position is estimated using the hall sensors arrangement, whereas in indirect method, it is obtained with the calculation of slip speed [12].

In this article, NSHC strategy is proposed for FOCOEWIM drive to achieve three level voltage across the output. To generate the control signals for two inverters in the proposed configuration NSHCPWM technique is used. In NSHCPWM, reference phasor is divided into two components. Based on the tip of the reference vector location NSHC is identified. Then the sub-hexagonal centre vector is used to realize the one of the component of reference phasor for generating the switching signals for Inv-I. The other vector is realized using Inv-II. To validate the proposed work, several simulation studies have been carried out in MATLAB and the corresponding results are reported.

\section{SYMMETRICAL CONFIGURATION OF OEWIM DRIVE}

A schematic of symmetrical dual inverter fed OEWIM drive is shown in Fig.1. Where $\mathrm{V}_{\mathrm{RX}}, \mathrm{V}_{\mathrm{YX}}$ and $\mathrm{V}_{\mathrm{BX}}$ denote the pole voltages of Inv-I and $\mathrm{V}_{\mathrm{R}^{\prime}{ }^{\prime}}, \mathrm{V}_{\mathrm{Y}^{\prime} \mathrm{X}^{\prime}}$ and $\mathrm{V}_{\mathrm{B}}{ }^{\prime} \mathrm{X}^{\prime}$ denote the pole voltages of Inv-II. In this configuration, two conventional two level inverters are fed with separate dc supply to avoid the flow of zero sequence currents into the motor. The individual pole voltages of Inv-I and Inv-II are $\mathrm{V}_{\mathrm{dc}} / 2$ or $-\mathrm{V}_{\mathrm{dc}} / 2$.

The effective phase voltage of this configuration is given by

$\mathrm{VZXZ}_{Z^{\prime} X^{\prime}}=\mathrm{V}_{Z X}-\mathrm{V}_{Z^{\prime}} \mathrm{X}^{\prime}$

Where $\mathrm{Z}=\mathrm{R}, \mathrm{Y}, \mathrm{B}$ 


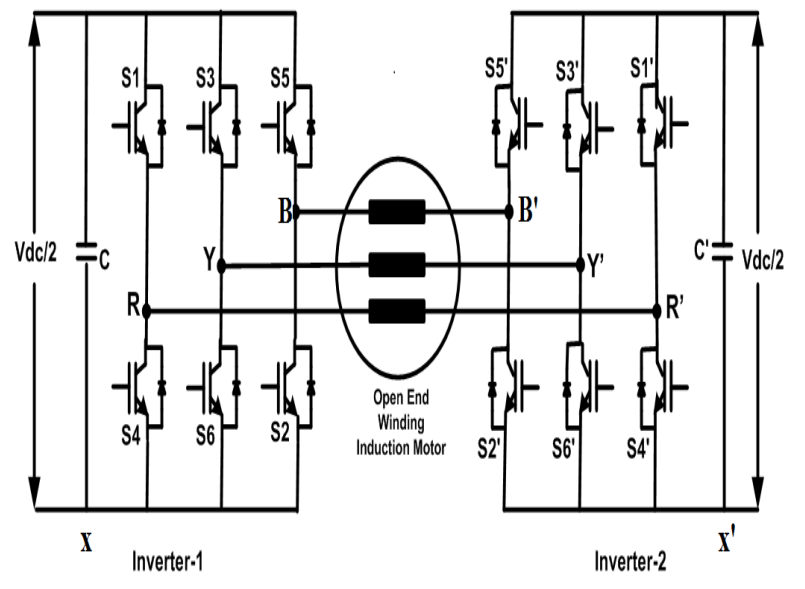

Fig. 1 Symmetrical dual inverter fed OEWIM drive

PWM techniques are generally used to control the output voltage and frequency of the inverter. A CMV is identified in the proposed configuration. Hence, the CMV across the terminals $\mathrm{X}$ and $\mathrm{X}^{\prime}$ is given by[3]-[4]

$$
\mathrm{V}_{X X}=\frac{\mathrm{V}_{\mathrm{RR}^{\prime}}+\mathrm{V}_{\mathrm{YY}}+\mathrm{V}_{\mathrm{BB}}}{3}
$$

The switching states of Inv-I and Inv-II are shown in Fig.2. When switch is on represented with' +' (or) 1 , when switch is off represented with "-'(or) 0.

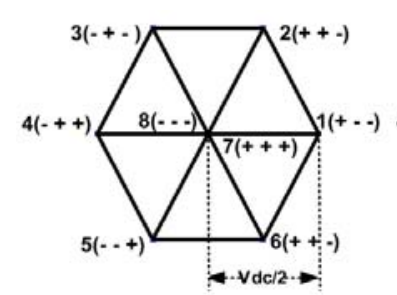

(a)

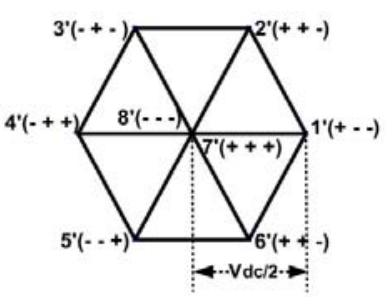

(b)
Fig. 2 Space vector locations of a) Inv-I and b) Inv-II

\section{NEAREST SUB-HEXAGONAL CENTER (NSHC) SWITCHING SCHEME}

The main principle of the proposed strategy is based on the tip of reference vector location nearest subhexagonal centre (NSHC) is identified and the corresponding space vector combinations are obtained by clamping one inverter and switching the other inverter[11-12].

\section{Inv-I:}

A. Realization of NSHC and switching signals for

In this proposed scheme, instantaneous reference voltages are used to find the NSHC. Modulation index (M) is defined as the ratio of reference voltage vector magnitude to the dc link voltage. From Fig. 3 it is shown that the tip of the reference vector is located outside the inner hexagon, the NSHC is identified using the following procedure. Let $\mathrm{V}_{\mathrm{R}}, \mathrm{V}_{\mathrm{Y}}$, and $\mathrm{V}_{\mathrm{B}}$ be the instantaneous reference phase voltages. If the magnitude of any phase is positive, it is designated as 1.if any phase magnitude is negative, it is represented as $0[[8],[10]$.Let ' $O V$ ' be the reference vector located in sector 13 which is outside inner sub hexagon. The reference vector $\mathrm{OV}$ can be realized by sum of two vectors namely OD and DV. In the proposed configuration, Inv-I is used to realize the vector $\mathrm{OD}$ which is the NSHC vector for reference vector OV and Inv-II is used to realize the vector DV. To generate the control signals for Inv-I NSHC vector is used [10].

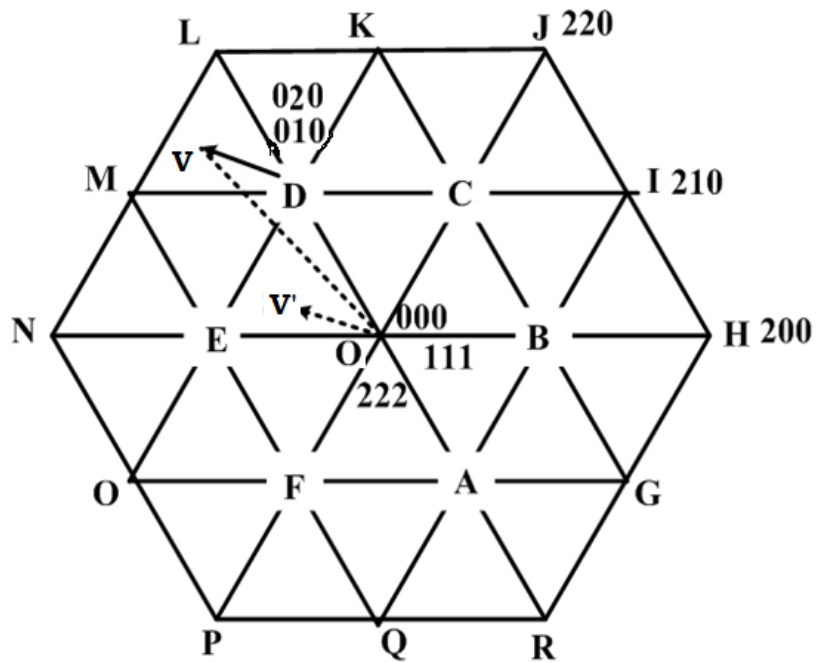

Fig. 3 Mapping of reference vector OS into inner sub-hexagon [10]

B. Inv-II Switching Pulses through inner subhexagon mapping:

Let $V_{\text {Rref, }} V_{\text {Yref }}$ and $V_{\text {Bref }}$ are the instantaneous reference voltages of the reference vector OV. Obtain the corresponding $\alpha$ and $\beta$ co-ordinates of the reference vector ( $\mathrm{V}_{\text {aref, }} \mathrm{V}_{\beta \text { ref }}$ ) using conventional 3- $\phi$ to 2- $\phi$ transformation [8][10]. The NSHC located near to the tip of the reference vector is identified ( $\mathrm{D}$ in the present case).Obtain the $(\alpha$, $\beta$ ) components of NSHC vector OD. Let $\left(\mathrm{V}_{\alpha \mathrm{NSHC}}, \mathrm{V}_{\beta \mathrm{NSHC}}\right)$ are the $(\alpha, \beta)$ coordinates of NSHC vector. The vector DV is realized by mapping the NSHC ' $D$ ' to the inner subhexagon $\mathrm{O}$. The mapping vector is represented as $\mathrm{OV}$ '. Then the coordinates of the vector $\mathrm{OV}^{\prime}$ is

$$
\begin{aligned}
& \mathrm{V} \alpha \mathrm{m}=\mathrm{V} \alpha \mathrm{ref}-\mathrm{V} \alpha \mathrm{NSHC} \quad \& \\
& \mathrm{~V} \beta \mathrm{m}=\mathrm{V} \beta \mathrm{ref}-\mathrm{V} \beta \mathrm{NSHC}
\end{aligned}
$$

Obtain the reference phase voltages VRm, VYm, VBm of mapping vector OV' using the 2- $\phi$ to $3-\phi$ transformation. In the proposed NSHC scheme, Inv-I is used to realize the vector OD which is the NSHC vector for reference vector $\mathrm{OV}$ and it is clamed at the vector OD. Inv-II is used to realize the vector DV and it is mapped into the inner sub-hexagon $\mathrm{O}$ with mapping vector OV'. With the use of two inverters on either side of OEWIM drive, reverse vector of $\mathrm{OV}^{\prime}$ must be supplied to realize the vector DV [10]. If Inv-I is used as switching inverter modified reference sinusoid are directly used to realize the vector DV without negation. In the proposed scheme, the role of clamping inverter and switching inverter gets reversed for every $60^{\circ}$. Based on the placement of effective time different time offset values are defined. Effective time is the time where the power is delivered from source to load. Using different time offset values NSHCPWM techniques are generated namely centric PWM and noncentric PWM. To generate the centric PWM time off-set is 
$\mathrm{T}_{\text {offset }}=\frac{{ }^{\mathrm{T}} \mathrm{Z}}{2}-\mathrm{T}_{\text {Minimum }}$

To generate various non-centric PWM techniques the time offset value is considered as

$$
\begin{aligned}
& \mathrm{T}_{\text {offset }}=-\mathrm{T}_{\text {Minimum }} \text { (Non-CentricPWM1) } \\
& \mathrm{T}_{\text {offset }}=\mathrm{T}_{\mathrm{S}}-\mathrm{T}_{\text {Maximum }} \text { (Non-CentricPWM2) }
\end{aligned}
$$

\section{INDIRECT FIELD ORIENTED CONTROLLED INDUCTION MOTOR DRIVE (IFOCIMD)}

In most of the industries ac drives are used as variable speed drives. Various control strategies are used in the past [11]-[12].But, these control strategies provide better steady state response poor dynamic response. To improve the dynamic response of the inverter-fed induction motor drives, induction motor drives operate as a separately excited dc drives to achieve the orthogonal control between torque producing and flux producing component of stator current[11]-[12].To achieve this we need to calculate the instantaneous rotor flux position. It can be represented as

$\theta_{\mathrm{e}}=\theta_{\mathrm{r}}+\theta_{\mathrm{S} 1}$

Where $\theta_{\mathrm{r}}=$ Rotor position angle

$\theta_{\mathrm{sl}}=$ Slip angle

In this article, rotor flux position angle $\left(\theta_{\mathrm{e}}\right)$ is acquired indirectly by using the Eq. (7).From the block diagram shown in Fig.4, it can be observed that the speed error with the help of conventional controller is converted into a torque controlling component $\mathrm{i}_{\mathrm{qs}}$ *of the stator current [12].This component of stator current is used to regulate the torque along with the slip speed [12].The other component of stator current is known as flux producing component $\mathrm{i}_{\mathrm{ds}} *$, obtained from field weakening control block [12].For the given permissible flux level, the required torque is

$\mathrm{T}_{\mathrm{e}}=\frac{3}{2} \frac{\mathrm{P}}{2} \frac{\mathrm{L}_{\mathrm{m}}}{\mathrm{L}_{\mathrm{r}}} \psi_{\mathrm{s}}^{*} \mathrm{I}_{\mathrm{qS}}^{*}[12]$

Then, the slip speed is given by

$$
\omega_{\mathrm{sl}}=\omega_{\mathrm{e}}-\omega_{\mathrm{r}}=\frac{\mathrm{R}_{\mathrm{r}}}{\mathrm{L}_{\mathrm{r}}} \frac{\mathrm{i}_{\mathrm{qs}}^{*}}{i_{\mathrm{ds}}^{*}}[12]
$$

The stator current components $\mathrm{i}_{\mathrm{ds}} *$ and $\mathrm{i}_{\mathrm{qs}} *$ along with the $\mathrm{i}_{\mathrm{ds}}$ and $\mathrm{i}_{\mathrm{qs}}$ from the motor currents are used to get the two-phase axis voltages[11-12]. These are converted into three phase reference voltages, from these voltages proposed decoupled NSHCPWM techniques are generated to get the switching pulses for the two conventional inverters in the proposed OEWIM drive.

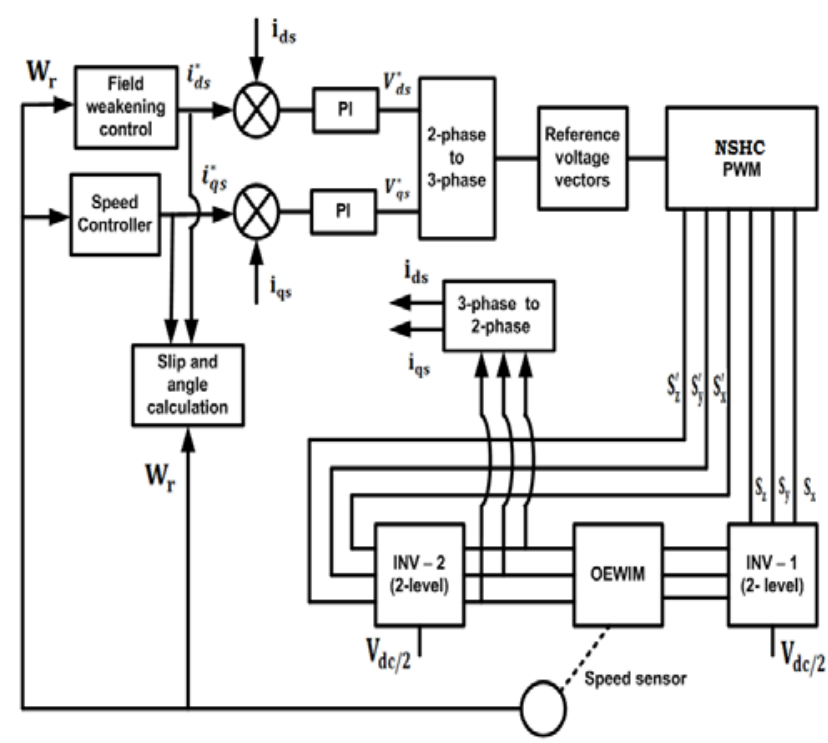

Fig. 4 Block diagram of IFOC

\section{RESULTS AND DISCUSSION}

To explore the proposed work, several simulation studies have been carried out on indirect field oriented control of OEWIM drive using NSHCPWM techniques. A dc voltage of $600 \mathrm{~V}$ is considered as effective voltage for the proposed symmetrical OEWIM configuration. Carrier frequency of $5 \mathrm{KHz}$ is chosen for simulation. The motor parameters are considered for simulation are $\mathrm{R}_{\mathrm{s}}=1.570 \mathrm{hm}, \mathrm{R}_{\mathrm{r}}=1.210 \mathrm{hm}, \mathrm{L}_{\mathrm{m}}=0.165$ Henry, $\mathrm{L}_{\mathrm{s}}=0.17$ Henry, $\mathrm{L}_{\mathrm{r}}=0.17$ Henry and $\mathrm{J}=0.089 \mathrm{Kg}-\mathrm{m}^{2}$.
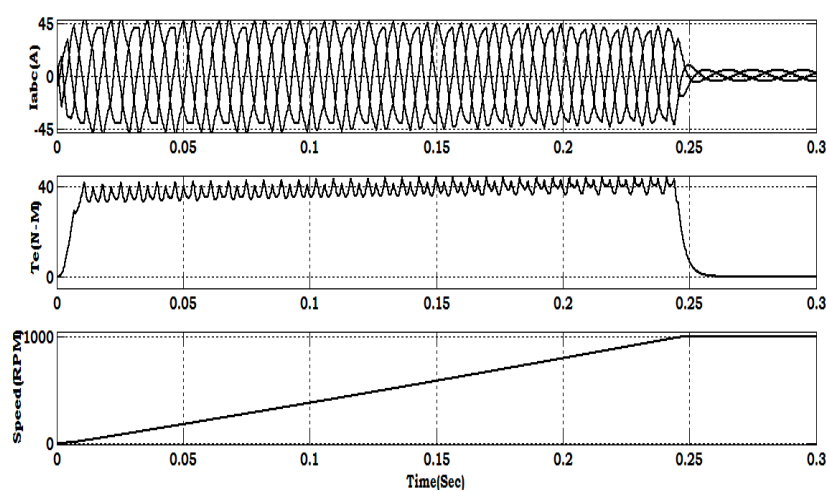

(a)
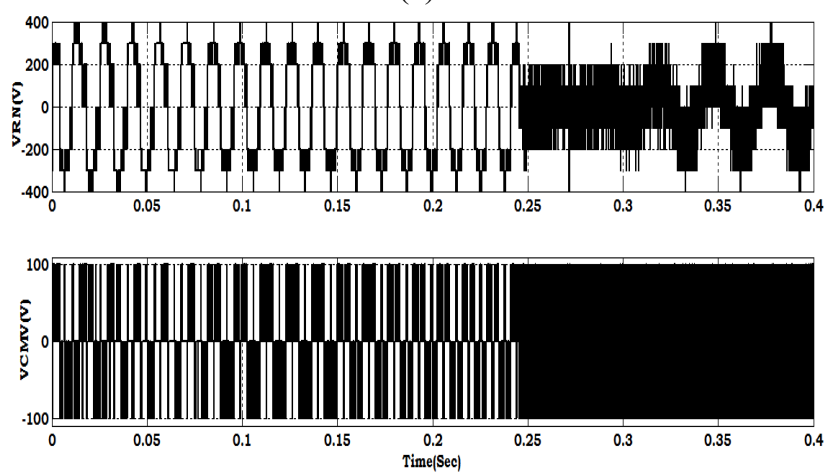

(b)

Fig. 5 Simulated traces at starting (a) Stator currents, Torque and Speed (b) Effective phase voltage (VRN) and CMV with Centric PWM 

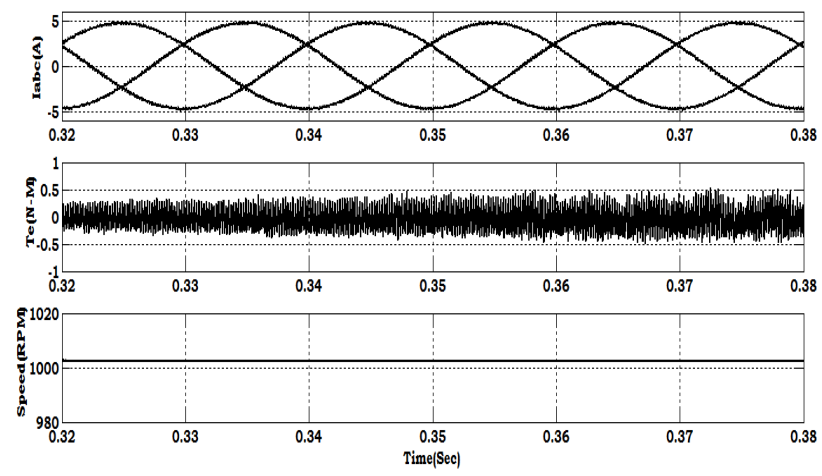

(a)
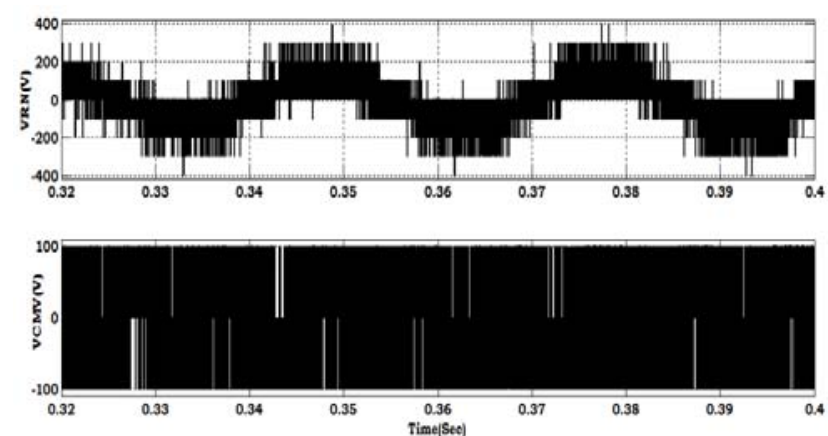

(b)

Fig. 6 Simulated traces at steady state (a) Stator currents, Torque and Speed (b) Effective phase voltage (VRN) and CMV with Centric PWM
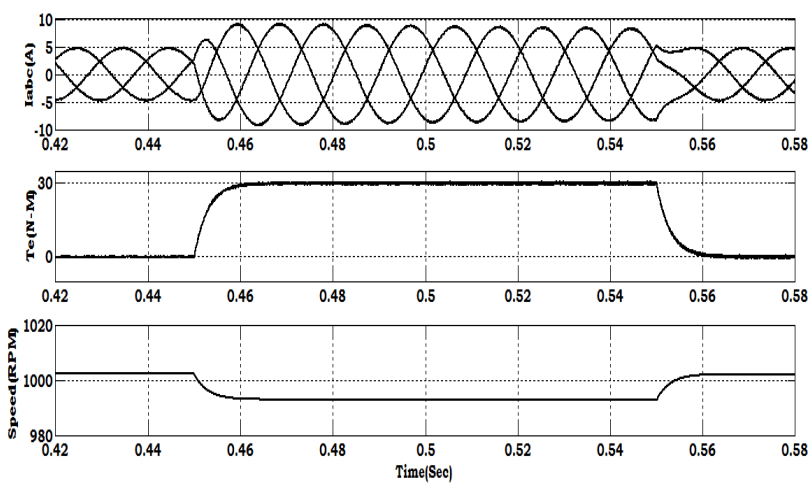

(a)
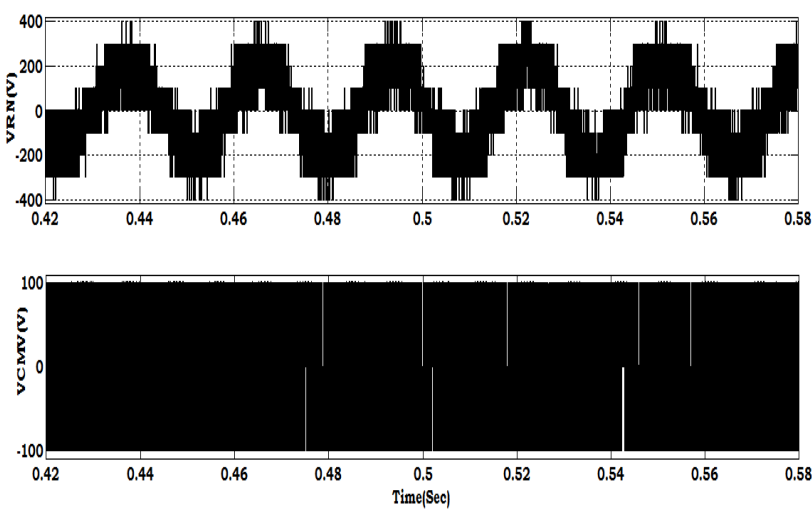

(b)

Fig. 7 Simulated traces at load case (a) Stator currents, Torque and Speed (b) Effective phase voltage (VRN) and CMV with Centric PWM
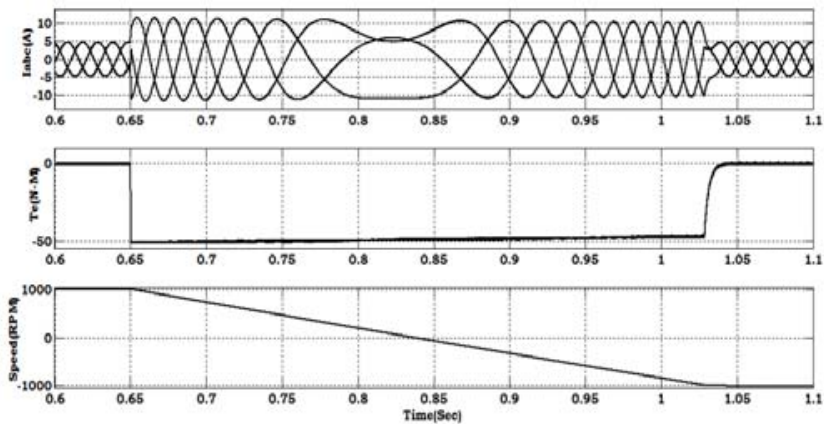

(a)
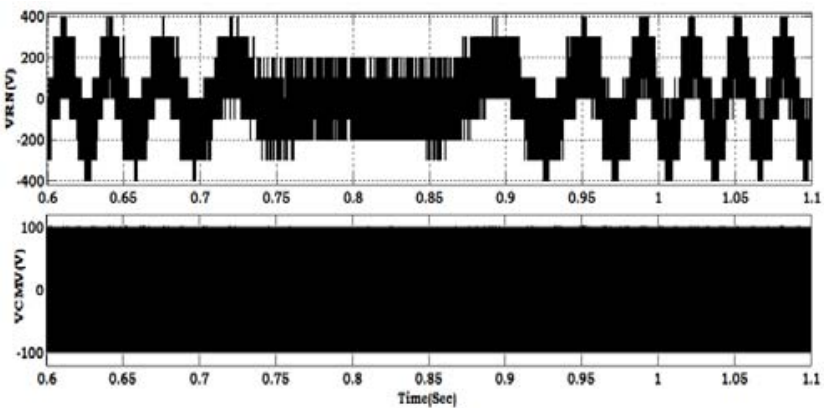

(b)

Fig. 8 Simulated traces at speed reversal case (a) Stator currents, Torque and Speed (b) Effective phase voltage (VRN) and CMV with Centric PWM
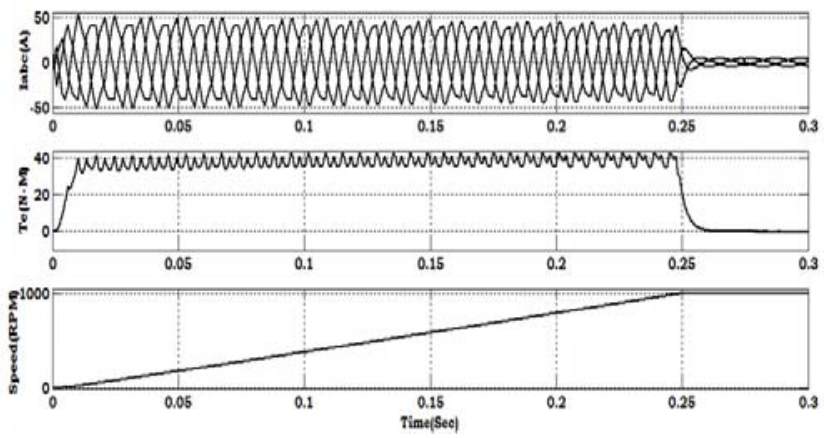

(a)
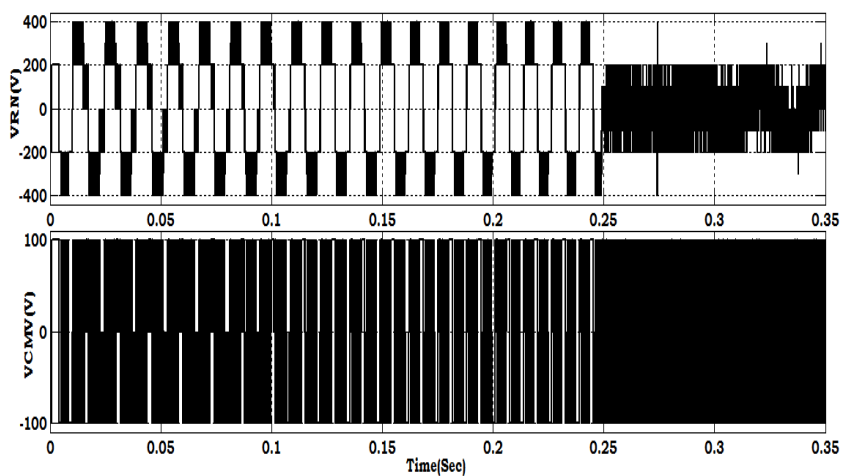

(b)

Fig. 9 Simulated traces at starting (a) Stator currents, Torque and Speed (b) Effective phase voltage (VRN) and CMV with Non-Centric PWM1 


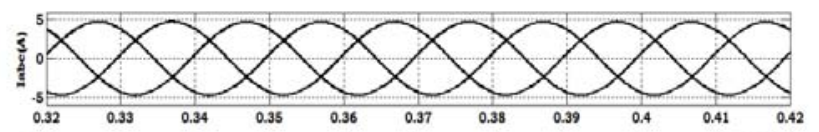

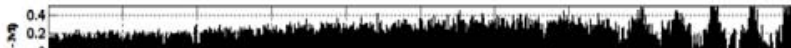

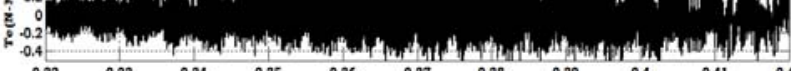

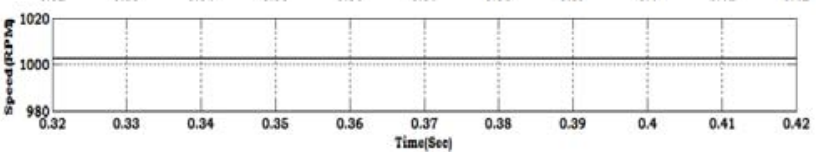

(a)

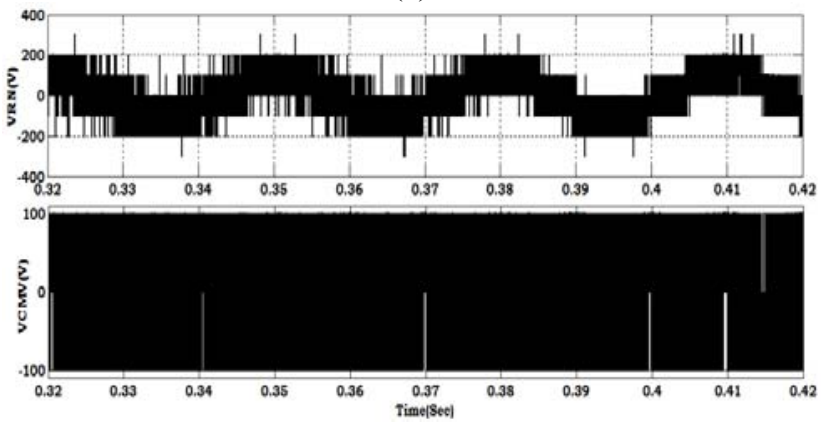

(b)

Fig. 10 Simulated traces at steady state (a) Stator currents, Torque and Speed (b) Effective phase voltage (VRN) and CMV with Non-Centric PWM1
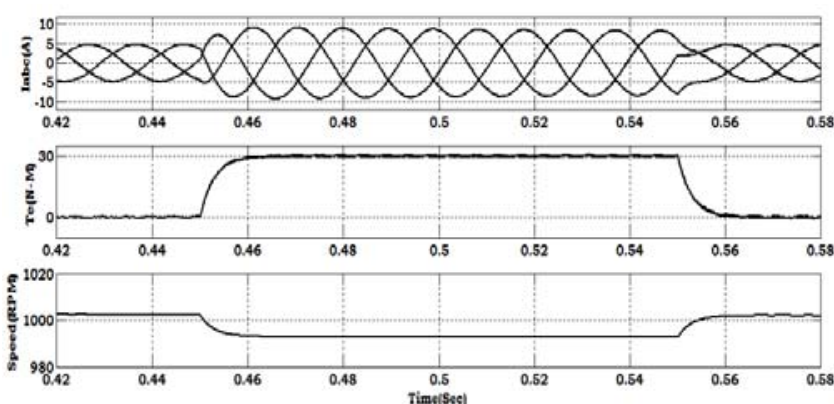

(a)
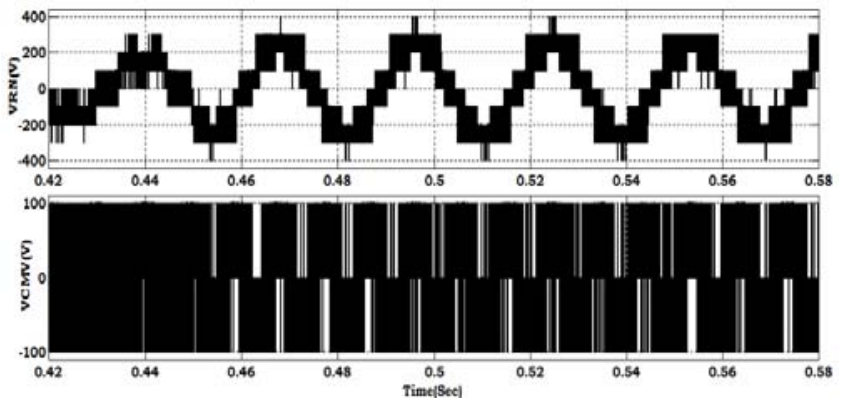

(b)

Fig. 11 Simulated traces at load case (a) Stator currents, Torque and Speed (b) Effective phase voltage (VRN) and CMV with Non-Centric PWM1
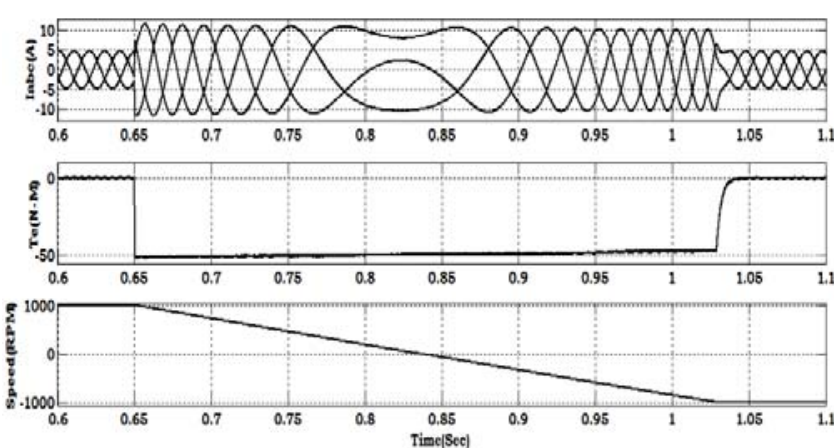

(a)

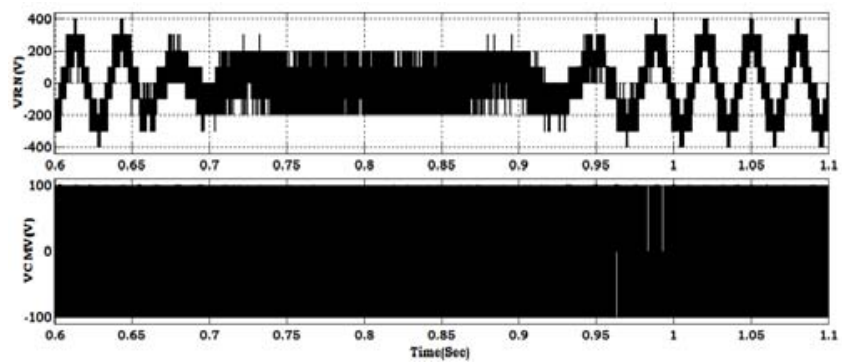

(b)

Fig. 12 Simulated traces at speed reversal case (a) Stator currents, Torque and Speed (b) Effective phase voltage (VRN) and CMV with Non-Centric PWM1
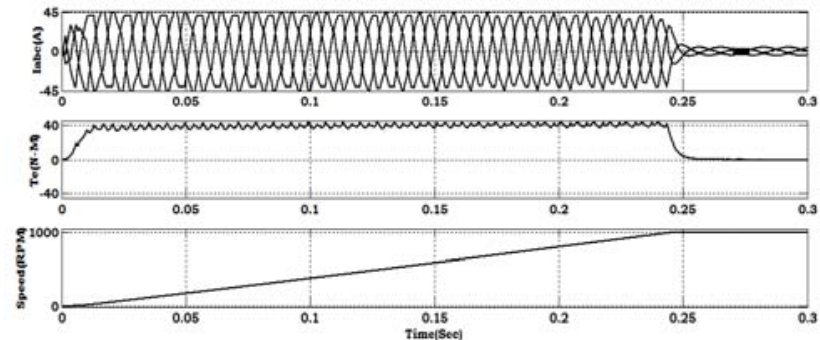

(a)
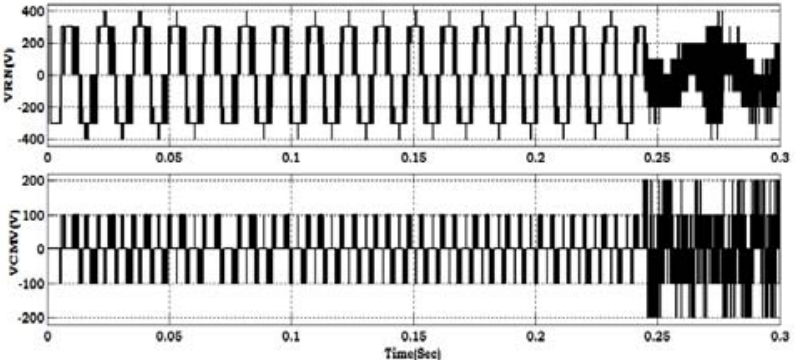

(b)

Fig. 13 Simulated traces at starting (a) Stator currents, Torque and Speed (b) Effective phase voltage (VRN) and CMV with Non-Centric PWM2

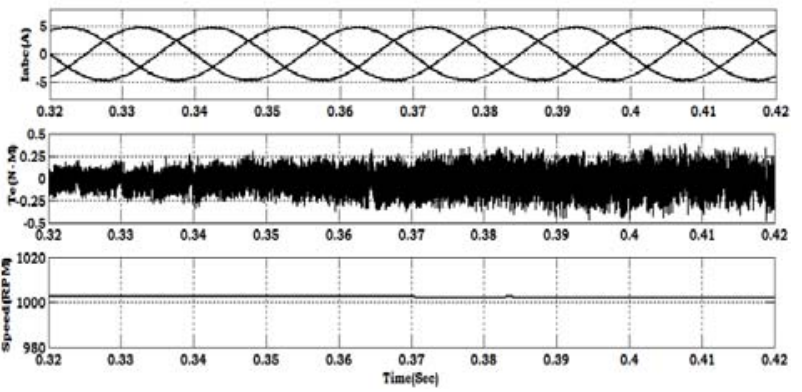

(a)

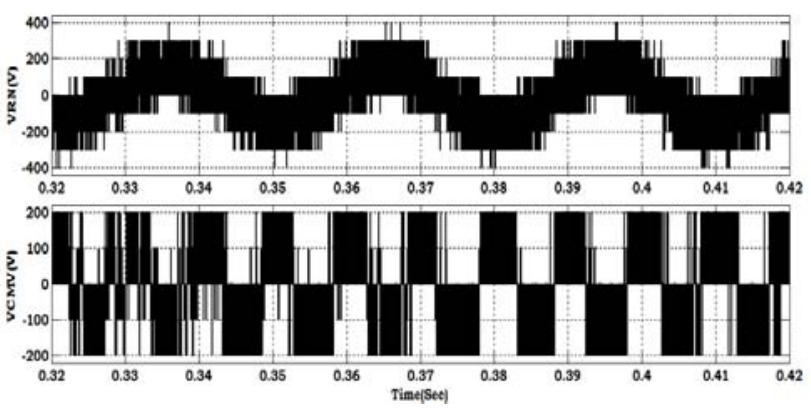

(b)

Fig. 14 Simulated traces at steady state (a) Stator currents, Torque and Speed (b) Effective phase voltage (VRN) and CMV with Non-Centric PWM2 

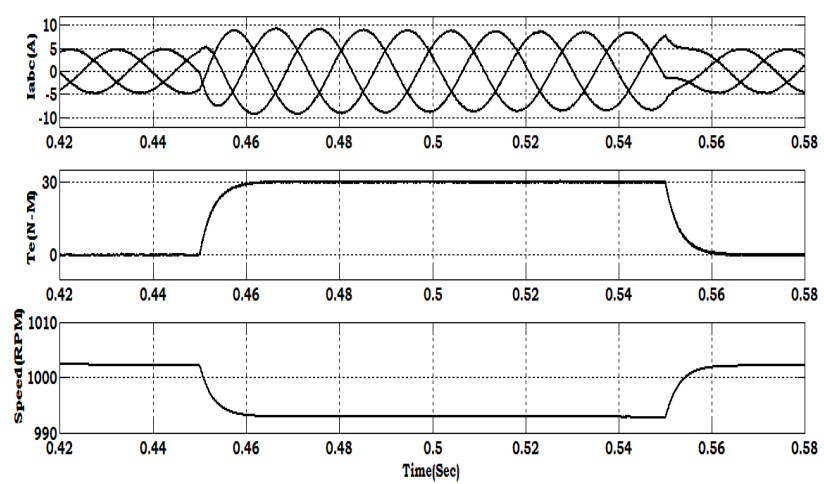

(a)
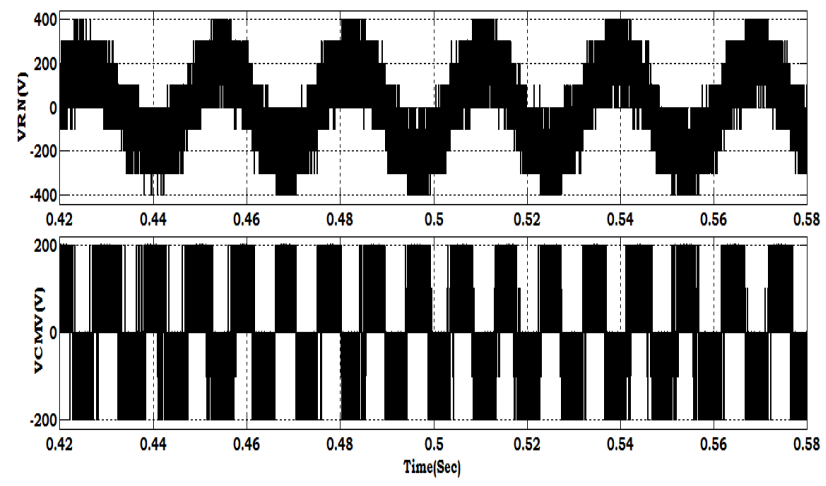

(b)

Fig. 15 Simulated traces at load case (a) Stator currents, Torque and Speed (b) Effective phase voltage (VRN) and CMV with Non-Centric PWM2
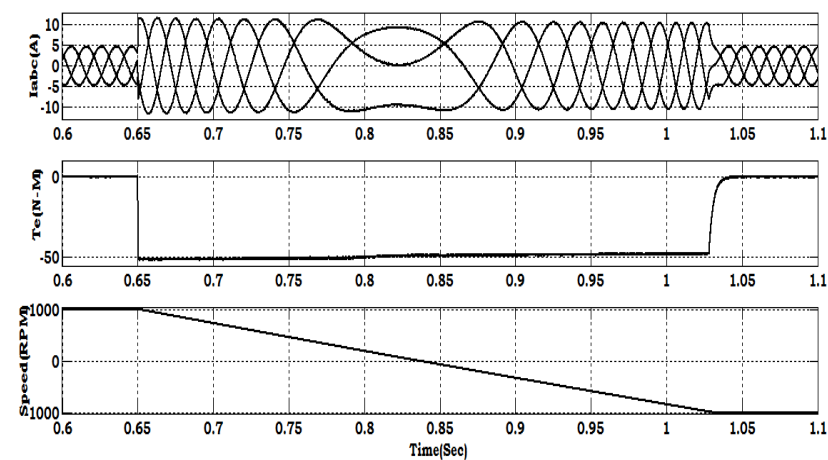

(a)
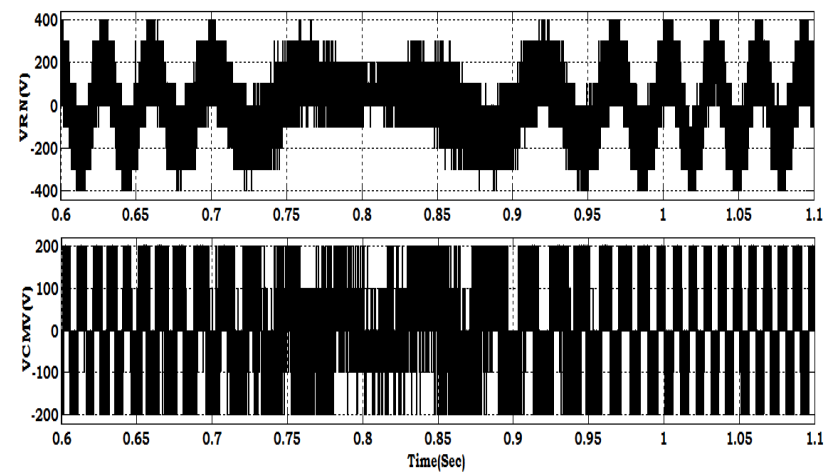

(b)

Fig. 16 Simulated traces at speed reversal case (a) Stator currents, Torque and Speed (b) Effective phase voltage (VRN) and CMV with Non-Centric PWM2
From Fig. 5, Fig. 9 and Fig. 13 it is observed that for centric and non-centric PWM techniques takes high stator current at starting to establish the required torque in addition to overcome the machine inertia. Once the machine establishes the required torque the speed of the rotor reaches to stable speed $1000 \mathrm{rpm}$ in the present case. It is also observed that modulation index is also increases as the speed of the machine increases. As the speed of the motor reaches to steady state, modulation index remains at constant value. At lower modulation index 2-level output voltage is generated. Once the machine reaches to steady state, machine takes less current than starting and the corresponding torque is very low. Except in NON-Centric PWM1method remaining PWM techniques generate 3level output voltage shown in Fig. 6, Fig. 10 and Fig. 14. A step load of $30 \mathrm{~N}-\mathrm{M}$ is applied at $0.44 \mathrm{sec}$ and removed at $0.55 \mathrm{sec}$ shown in Fig. 7, Fig. 11 and Fig. 15. As the load is applied on motor, stator takes more current to establish the required torque proportionately torque is also increases and the speed of the machine got reduced. Speed reversal cases for all the proposed PWM techniques are shown in Fig.8, Fig.12 and Fig.16.It is observed from the speed reversals plots that the frequency of the stator currents decreases as the speed reversals taking place from $1000 \mathrm{rpm}$ to $-1000 \mathrm{rpm}$. Therefore, torque becomes negative. As the speed of the machine reverses along with the frequency decrement in stator currents modulation index also got changed. It is also observed from the results that the CMV of the proposed configuration becomes $\pm \mathrm{V}_{\mathrm{dc}} / 6( \pm 100 \mathrm{~V})$ except in Non-Centric PWM2 technique $\left( \pm \mathrm{V}_{\mathrm{dc}} / 3( \pm 200 \mathrm{~V})\right.$. All the proposed techniques generate effective phase voltage of magnitude $\pm 2 \mathrm{~V}_{\mathrm{dc}} / 3( \pm 400 \mathrm{~V})$.

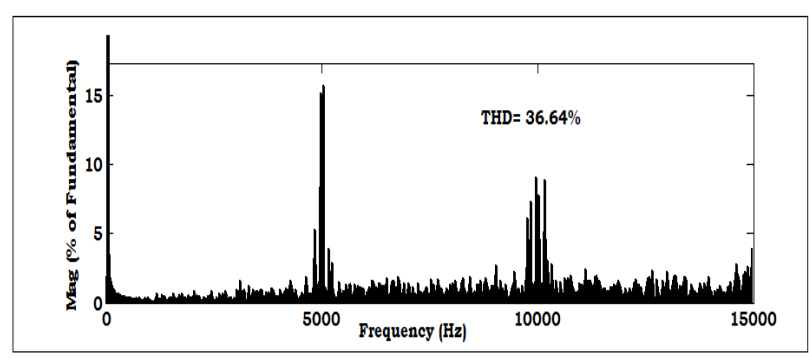

(a)

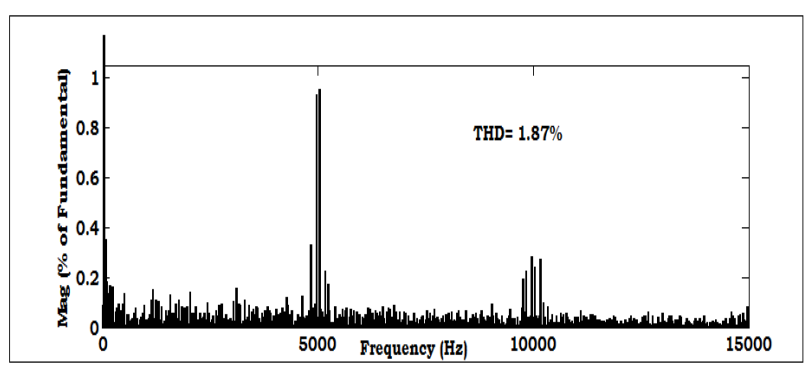

(b)

Fig. 17 Harmonic spectra of ((a) Effective phase voltage (VRN) b) Stator current with Centric PWM 


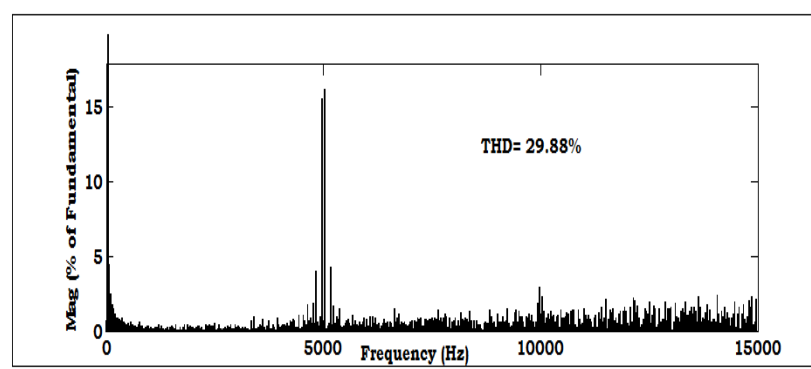

(a)

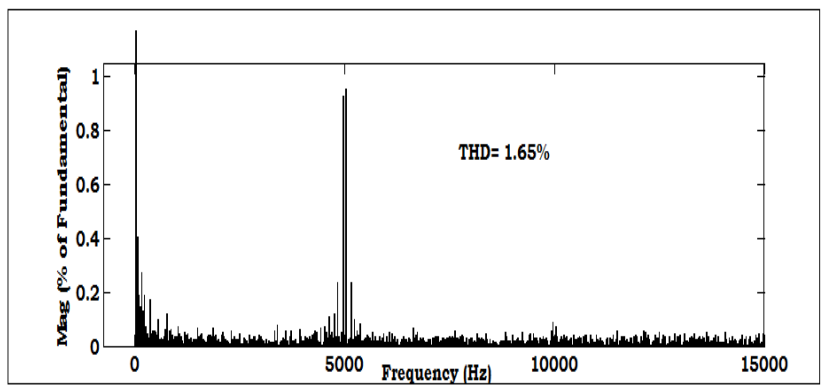

(b)

Fig. 18 Harmonic spectra of ((a) Effective phase voltage (VRN) b) Stator current with Non-Centric PWM1

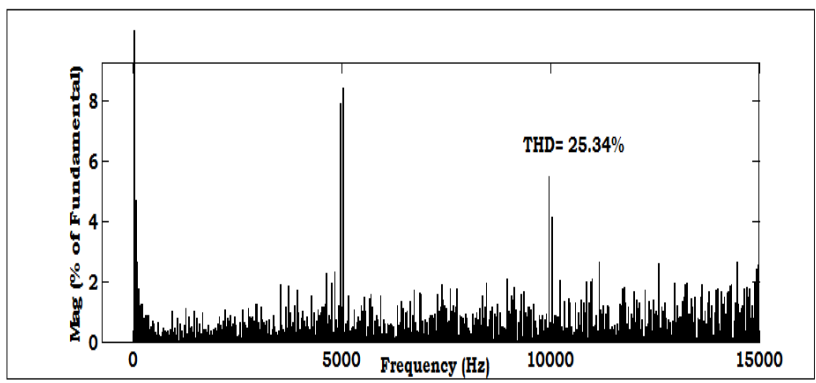

(a)

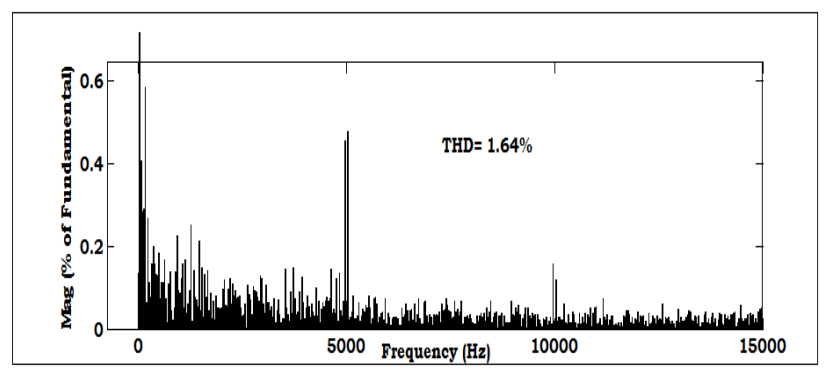

(b)

Fig. 19 Harmonic spectra of ((a) Effective phase voltage (VRN) b) Stator current with Non-Centric PWM2

\section{CONCLUSIONS}

In the proposed work nearest sub-hexagonal centre (NSHC) PWM technique is implemented for indirect field oriented controlled OEWIM drive. NSHC PWM technique is implemented using the reference phase sinusoids. In NSHCPWM, each inverter is clamped and switched for every $60^{\circ}$. In this work three PWM techniques Centric PWM, Non-Centric PWM1 and NonCentric PWM2 are implemented for FOCOEWIM drive.
Non-Centric PWM techniques clamp each phase to either positive or negative link voltage for 120 degrees in every fundamental cycle and hence reduce the switching loss by $33.33 \%$ when compared with the Centric PWM technique. The total harmonic distortions of the motor phase voltage and stator current in Centric PWM are more compared to Non-Centric PWM techniques. It is observed that there is a gradual decrement of the \%THD in motor phase currents. Hence Non-Centric PWM techniques give the better performance over Centric PWM technique. The simulation results show the validity of the proposed work.

\section{REFERENCES}

[1] STEMMLER, H. - GUGGENBACH, P.: Configurations of high power voltage source inverter drives, EPE 1993, Brighton, U.K., pp.7-12.

[2] HOLTZ, J.: "Pulse width modulation - A survey" IEEE Trans. Ind. Electron. Vol. 39, No.5, Dec. 1992, pp.410-420.

[3] SOMASEKHAR, V. T. - GOPAKUMAR, K. SHIVA KUMAR, E. G., - SINHA, S. K.: “A space vector modulation scheme for a dual two level inverter fed open-end winding induction motor drive for the elimination of zero sequence currents," EPE J., Vol. 12, No. 2, pp. 26-36, May 2002.

[4] CHEN, S. - LIPO, T. A. - FITZGERALD, D.: "Modeling of motor bearing currents in PWM inverter drives," IEEE Trans. Ind. Applicat., Vol. 32, pp. 1365-1370, Nov./Dec. 1996.

[5] BLASKO, V.: "Analysis of a hybrid PWM based on modified space-vector and triangle-comparison methods" IEEE Trans. Ind. Applicat., Vol. 33, No. 3, May/Jun 1997, pp. 756-764.

[6] NARAYANAN, G. - RANGANATHAN, V. T.: "Analytical evaluation of harmonic distortion in PWM AC drives using the notion of stator flux ripple IEEE Trans. Power Electron., Vol. 20, No. 2, Mar. 2005, pp. 466-474.

[7] NARAYANAN, G. - KRISHNAMURTHY, H. AYYANAR, R. - Di ZHAO: "Space vector based hybrid techniques for reduced current ripple" IEEE Trans. Ind. Applic., Vol. 55, No. 4, April 2008, pp. 1614-1626.

[8] SHINY, G. - BAIJU, M R.: "Space vector PWM scheme without sector identification for an open-end winding induction motor based 3-level inverter "in Industrial Electronics, 2009. IECON '09. 35th Annual Conference of IEEE, pp. 1310-1315. Nov, 2009.

[9] BRAHMANANDA REDDY, T. - AMARNATH, J. - DSUBBARAYUDU: "Improvement of DTC performance by using hybrid space vector Pulse width modulation algorithm" International Review of Electrical Engineering, Vol. 4, No. 2, Jul-Aug., 2007, pp. 593-600. 
[10] CHUNG, D.W. - KIM, J. S. - SUL, S. K.: "Unified modulation technique for real-time three phase power conversion". IEEE Trans. Ind. Applicat., Vol. 34, pp. 374-380, Apr., 1998.

[11] BLASKE, F.: "The principle of field orientation as applied to the new trans vector closed-loop control system for rotating field machines", Siemens Rev., vol. 34, no. 3, pp. 217-220, May 1972.

[12] SATYANARAYANA, K. - AMARNATH, J. KAILASA RAO, A. - BRAMHANANDA REDDY, T.: "Simplified Vector Control Algorithm for Induction Motor Drives Based on Sophisticated Look-up Tables" International review on Modelling and Simulations, Vol. 3, No. 5, Oct. 2010.

Received December 24, 2017, accepted February 28, 2018

\section{BIOGRAPHIES}

Dr. Teegala Bramhananda Reddy graduated from Sri Krishna Devaraya University, Anantapur in the year 2001. He received M.E degree from Osmania University, Hyderabad, India in the year 2003 and Ph.D from J. N. T. University, Hyderabad in the year 2009.
$\mathrm{He}$ is presently working as Professor and Head of Electrical and Electronics Engineering Department, G. Pulla Reddy Engineering College (Autonomous), Kurnool, India. He presented more than 80 research papers in various national and international conferences and journals. His research area includes PWM techniques, $\mathrm{DC}$ to AC converters and control of electrical drives.

Dr. Munagala Surya Kalavathi obtained her B.Tech degree from S.V.University in the year 1988 and M.Tech degree from same university in the year 1992. Obtained her doctoral degree from JNTU, Hyderabad and post doctoral from CMU, USA. She is presently working as professor in JNTU college of Engg. Hyderabad. She has published more than 70 research papers. Her research area includes simulation studies on transients of different power system equipment.

Mahamkali Ranjit received B. Tech degree from Nalanda Institute of Engineering and Technology, Guntur, Andhra Pradesh in the year 2006. He received M.Tech degree in power electronics and Industrial drives from JNT University in the year 2011. Currently, he is with VNR Vignana Jyothi Institute of Engineering \& Technology, Hyderabad, as an Assistant Professor. His areas of interests are power electronic control of drives. 